\title{
Effects of a yoga program on health, behaviour and learning ability in school children: a single arm observational study
}

\begin{abstract}
Background: Learning difficulties, Stress and behavioural problems are widely prevalent in high school children that contribute to dropouts and poor performance. Yoga as a mind body intervention has been shown to improve performance in pilot studies. In this large observational study we assess the impact of yoga intervention on learning, cognitive abilities, behaviour and health in high school children.
\end{abstract}

Methods: Seven hundred and sixty eight schools across fifty talukas in Karnataka with around seven thousand six hundred and one children were assessed on improvements in learning, cognition, behaviour and health following two months of yoga intervention. Physical education teachers from these schools were trained to impart yoga intervention over two months to students of both higher primary and high school. Assessments were done by class teachers and parents of students who were not involved in imparting intervention.

Results: There was a significant improvement in health, learning ability, cognitive ability, behaviour, and positive emotions and decrease in negative emotions (all p's $<0.001$ ). The effect size of change was modest for emotions, behaviour and cognitive ability and large for learning ability and health.

Conclusion: The results suggest beneficial effects of yoga intervention in higher primary and high school children.

Keywords: yoga, performance, learning, cognition, adolescents, school children
Volume 5 Issue I - 2017

\author{
Sathish Vhavle,' Raghavendra Rao, ${ }^{2}$ Majunath \\ NK,' Amritanshu Ram R ${ }^{2}$ \\ 'Swami Vivekananda Yoga, Anusandhana Samsthana, India \\ ${ }^{2}$ Healthcare Global Enterprises Itd, India
}

Correspondence: Raghavendra Rao M, PhD, Senior Scientist and Head CAM program, 5 Healthcare Global Enterprises Itd, No 8, P Kalinga Rao Rd, Sampangiramnagar, Bengaluru, India, Tel +919916488864, Email raghav.hcgrt@gmail.com

Received: December 26, 2016 | Published: January 03, 2017

\section{Introduction}

Educators, researchers, and health care providers working with children have long been interested in understanding what causes children with average intelligence to suffer from academic underachievement, particularly when these academic difficulties are not the result of physical, social and environmental factors. Behavioural problems in children including mood disorders, emotional distress, peer pressures, learning disorders and adjustment problems are all said to contribute towards academic underachievement. ${ }^{1}$ For example emotional distress, disrupted cognitive functioning, and deterioration in academic performance have all been theorized to be possible results of depressive moods that have resulted from peer pressures, family conflicts, and having to contribute to financial needs of the family. ${ }^{2}$ School dropout rates have also been attributed to learning difficulty and poor academic performance. ${ }^{3}$ Schemes like mid-day meals have failed to improve classroom attendance. ${ }^{4}$ Dropout rates in Karnataka according to national sample survey statistics is around $7.9 \%$ in rural areas and $3.1 \%$ in urban areas with marginally more dropout rates in males compared to females. Specific clinical features of depression such as reduced attention span, lethargy, poor concentration and memory, as well as abridged task perseverance are all factors that have emerged as obstacles to effective learning. Furthermore, poor academic performance has been associated with an increase in social and behavioral problems. ${ }^{5}$ Though overt clinical depression is seen in a few a majority of they express depressive mood swings that are usually seen in adolescents. The stress to perform and its accompanying physiological and behavioural stress response can result in mood swings, emotional distress, loss of sleep and cognitive impairment. Poor classroom performance is consistently demonstrated in children with depressive symptoms when no other intervening learning disability is present. $^{6}$ Negative correlations between severity of depressive symptoms and intelligence scores, particularly by adolescence, have also been reported. ${ }^{7,8}$ Similarly, a weaker performance on a variety of measures assessing cognitive functioning has been observed in cohorts of children with symptoms of depression. ${ }^{8}$ These children have also exhibited a weaker performance on academic achievement measures including mathematics and knowledge clusters ${ }^{5-9}$ and reading abilities. ${ }^{10}$ In addition, behavioural manifestations of depression including attention difficulties. ${ }^{8,11-14}$

It has been reported that student fatigue also markedly increases from elementary school to junior high school..$^{15}$ Identifying fatiguerelated factors is thus important for preventing increased levels of fatigue during this transition period.

Exercises and play have helped students learn ways to cope with emotional, social and mental stressors they endure as teenagers. ${ }^{16}$ Exercise, group activities and play have been known to improve selfesteem that's needed to overcome the emotional upheavals during the adolescence age. ${ }^{17}$ Regular physical activity and exercise is known to produce strong healthy bones and muscles, reduce risk of obesity and chronic diseases, reduce feelings of anxiety and promote psychologic wellbeing..$^{18}$ Moreover, obesity is a growing problem in teens and participation in physical activity decreases as age or grade in school increases further contributing to this problem. ${ }^{17}$ Physical activity can improve self-image, self-confidence, mood, relieve stress tension and premenstrual tension, increased alertness, increased energy and increased ability to cope with stress. ${ }^{19}$ Yoga is one such mind body intervention that uses postures or asanas, breathing exercises and pranayama (regulated nostril breathing) that has similar metabolic 
effects as an exercise. ${ }^{20}$ Studies have shown that while breathing through right nostril facilitates increase in basal metabolic rate and reduces obesity, ${ }^{21}$ left nostril breathing has anxiolytic effects ${ }^{22}$ Pranayama also influences tidal volume. ${ }^{23}$ Similarly as an as are known to improve strength, flexibility, ${ }^{24}$ and heart rate variability ${ }^{25}$ that enhances cardio protective effects, ${ }^{25}$ performance, endurance and stamina in children. ${ }^{26}$ Yoga has also been shown to improve self esteem and promote mental health in adolescents. ${ }^{27}$ In this study we evaluated the effects of two months yoga intervention in primary and high school students across all districts in Karnataka.

In this study teachers from each selected taluk from each district in Karnataka trained in yoga will evaluate the effects of two months of yoga in adolescent school children studying in higher primary and high school in rural districts of Karnataka on executive functions and their performance.

\section{Study objectives}

i. To integrate yoga into rural education in higher primary and high schools in each selected taluk of different districts in the state.

ii. To evaluate the effects of yoga on abilities of learning, cognition, behaviour and health in higher primary and high school children.

a. Hypothesis: Yoga will improve abilities of learning, cognition, behaviour and health in higher primary and high school children following two months of intervention.

\section{Methods}

\section{Subjects}

All School children in higher primary (6th -7 th grade) and high school (8th -9th grade) enrolled in schools that were selected for participation in the yoga education program by the education department were assessed before and after two months of yoga intervention. The program was carried out over a period of two consecutive years during the period between Novembers to February in both years. Assessments in this study were carried out by respective class teachers who were not involved in imparting the intervention. The yoga intervention was impacted by physical education teachers who had undergone an intensive residential training program. This was a state program that enrolled teachers and students of schools from all thirty districts. A total of six thousand fifty seven schools were selected for the program covering five lakh six thousand nine hundred seventy four students. Among these only schools with adequate teacher to student ratio and different teachers for specific grades were selected to participate. Only those students were selected that satisfied the selection criteria.

\section{Selection criteria for subjects}

Inclusion criteria: a) Higher primary and high school children of both sexes. b) Age between 12- 15years.

Exclusion criteria: a) Those with h/o congenital heart disease, motor and mental retardation. b) Those with h/o epilepsy, severe exercise induced asthma. c) Fevers or infection at time of screening and recruitment.

Outcome measures: a) Student checklist filled by both teachers and their parents. ${ }^{27}$

\section{Intervention}

Yoga program: The Yoga intervention comprised a series of asanas, pranayama, meditation and relaxation given over a one hour period daily 6 days a week for 2 months. The classes started with loosening stretches, breathing exercises followed by eight asanas intersped with yogic relaxation. This was followed by pranayama (regulated nostril breathing). Similar program had been used earlier in school students that showed improvement in spatial and verbal memory scores. ${ }^{28,29}$

Data analysis: Data was analysed using SPSS 18.0 for Windows. Mean scores for learning ability, cognition, health, behaviour and emotions were compared before and after intervention using paired $t$ test. The effect sizes of change were determined for each variable.

\section{Results}

The mean age of the study population was ....... Years. The number of schools that participated in the program and its geographical location is given under Table 1. Number of schools selected for assessments is given in Table 2. Among the eligible 9547 students around 7601 students were assessed.

\section{Learning abilities}

There was a significant improvement in learning abilities such as oral comprehension $(p<0.001)$, listening $(p<0.001)$, reading $(p<0.001)$ and writing $(\mathrm{p}<0.001)$ following yoga intervention (See Table 3, Figure 1).

There was a significant improvement in eyesight $(p<0001)$, sports activities $(p<0001)$, sickness prevention $(p<0001)$ and health $(p<0001)$ following yoga intervention (Table 4 and Figure 2$)$.

\section{Cognitive abilities}

There was a significant improvement in concentration $(p<0.001)$, intellect $(p<0.001)$, memory $(p<0.001)$, intelligence $(p<0.001)$, learning $(p<0.001)$, reasoning $(p<0.001)$, interaction $(p<0.001)$, direct speech $(\mathrm{p}<0.001)$, and attention $(\mathrm{p}<0.001)$, following yoga intervention (Table 5 and Figure 3 ).

\section{Negative emotions}

There was a significant decrease in negative emotions $(p<0.001)$ such as being unhappy $(p<0.001)$, fear $(p<0.001)$, stubborn $(p<0.001)$, being reserved $(p<0.001)$, impulsive $(p<0.001)$, feeling laziness $(p<0.001)$ and loneliness $(p<0.001)$ (Table 6 and Figure 4$)$.

\section{Positive emotions}

There was a significant improvement in positive emotions such as discipline $(p<0.001)$, accommodating $(p<0.001)$, respect $(p<0.001)$, organization capacity $(\mathrm{p}<0.001)$, being social $(\mathrm{p}<0.001)$ and obedient $(\mathrm{p}<0.001)$ (Table 7 and Figure 5).

\section{Effect size}

Effect size was large for learning and health and moderate for cognition and emotions See Table 8.

\section{Overall results}

The implementation of yoga education program and yoga in schools in various districts of Karnataka showed improvements in all indices of learning and cognitive function in primary and high school students. The results showed beneficial finding with yoga with maximum change being observed in listening, reading, writing indicating better attention and sports indicating healthy physically active lifestyle. There was also an overall improvement in concentration, memory, mathematical ability, discipline and overall personality development following this program. 
Table I List of schools, students selected in district and taluks to undergo Yoga assessments

\begin{tabular}{|c|c|c|c|c|c|c|c|c|c|}
\hline $\begin{array}{l}\text { Sl. } \\
\text { No }\end{array}$ & District & $\begin{array}{l}20 \mathrm{II}-20 \mathrm{I} \\
\text { Taluks }\end{array}$ & $\begin{array}{l}220 I 2-2013 \\
\text { taluks }\end{array}$ & $\begin{array}{l}\text { Selected } \\
\text { taluks }\end{array}$ & $\begin{array}{l}\text { Total schools } \\
\text { ( I |-| 2\& | 2-13) }\end{array}$ & $\begin{array}{l}\text { Selected } \\
\text { schools }\end{array}$ & $\begin{array}{l}\text { Total Students } \\
\text { Trained in Yoga }\end{array}$ & $\begin{array}{l}\text { Total students } \\
\text { eligible for } \\
\text { Assessment }\end{array}$ & $\begin{array}{l}\text { Selected students } \\
\text { for assessment }\end{array}$ \\
\hline $\mathrm{I}$ & Bagalkote & 2 & 3 & 5 & 386 & 47 & 13526 & 1140 & 663 \\
\hline 2 & Belgaum & 3 & 3 & 2 & 417 & 17 & $3|77|$ & 38 & 23 \\
\hline 3 & Bijapur & 0 & 2 & 2 & 175 & 43 & 17318 & 792 & 792 \\
\hline 4 & Chitradurga & 2 & I & 3 & 235 & 132 & 14640 & 745 & 235 \\
\hline 5 & Dharawad & 0 & 4 & 2 & 338 & 19 & 43543 & 159 & 159 \\
\hline 6 & Davangere & 0 & 2 & 2 & 165 & 29 & 10326 & 531 & 505 \\
\hline 7 & Gadag & 0 & 3 & I & 271 & 16 & 35501 & 225 & 210 \\
\hline 8 & Yadgiri & I & I & 2 & 136 & 15 & 15015 & 300 & 114 \\
\hline 9 & Bellary & 2 & I & I & 230 & 20 & 16011 & 504 & 490 \\
\hline 10 & Koppala & 0 & I & I & 70 & 09 & 5625 & 153 & 153 \\
\hline II & Raichur & I & I & I & 188 & 25 & 17755 & 500 & 363 \\
\hline 12 & Bidar & I & I & I & 144 & 10 & 4551 & 112 & 111 \\
\hline 13 & Gulbarga & I & 2 & I & 273 & 6 & 43838 & 150 & 147 \\
\hline 14 & Madikeri & 0 & I & I & 89 & 14 & 10348 & 182 & 176 \\
\hline 15 & Mandya & 0 & 2 & 2 & 120 & 32 & 17181 & 639 & 628 \\
\hline 16 & Mysore & 2 & 4 & 6 & 464 & 77 & 31518 & 1032 & 633 \\
\hline 17 & Hassan & I & 2 & I & 227 & 03 & 38806 & 21 & 21 \\
\hline 18 & Ramanagar & I & 2 & 2 & $24 I$ & 50 & 16879 & 629 & 567 \\
\hline 19 & Chamarajnagar & 0 & I & I & 69 & 5 & 4485 & 70 & 69 \\
\hline 20 & Tumkur & 0 & 2 & I & 160 & 13 & 22239 & 237 & 217 \\
\hline 21 & Kolar & I & I & I & 121 & 19 & 6300 & 165 & 146 \\
\hline 22 & Chikkamagalur & 2 & I & I & 186 & 05 & 10220 & 90 & 89 \\
\hline 23 & D.K.Mangalore & 0 & I & I & 57 & 09 & 2730 & 90 & 90 \\
\hline 24 & Karwar & I & 6 & 4 & 556 & 16 & 14182 & 250 & 240 \\
\hline 25 & Haveri & 0 & 2 & 2 & 139 & 38 & 9815 & 200 & 185 \\
\hline 26 & Shimoga & I & I & I & 90 & 12 & 8620 & 298 & 290 \\
\hline 27 & Udupi & 0 & 3 & 2 & 235 & 47 & 6931 & 295 & 285 \\
\hline 28 & Chikkaballapura & 0 & I & 0 & 22 & 0 & 1320 & 0 & 0 \\
\hline 29 & Bangalore (urban) & 0 & I & 0 & 93 & 0 & 18600 & 0 & 0 \\
\hline \multirow[t]{2}{*}{30} & Bangalore(r) & 0 & I & 0 & 86 & 0 & 17200 & 0 & 0 \\
\hline & TOTAL & 22 & 55 & 50 & 6057 & 728 & 506794 & 9547 & 7601 \\
\hline
\end{tabular}

Table 2 Number of schools selected for assessments

\begin{tabular}{llllll}
\hline Year & No of schools & $\begin{array}{l}\text { Students trained in } \\
\text { yoga }\end{array}$ & No of taluks & \multicolumn{2}{l}{ Sample of assessments } \\
\hline $2011-12$ & 1832 & 124278 & 22 & Selected taluks Selected schools & Selected students \\
$2012-13$ & 4225 & 382516 & 55 & 50 & 728 \\
Total & 6057 & 506794 & 77 & 50 & 7601 \\
\hline
\end{tabular}

Table 3 Learning abilities following yoga intervention

\begin{tabular}{lll}
\hline Learning abilities & PRE & POST \\
\hline Oral & $2.85 \pm 0.87$ & $3.52 \pm 0.68$ \\
Listening & $2.83 \pm 0.88$ & $3.53 \pm 0.66$ \\
Reading & $2.82 \pm 0.93$ & $3.54 \pm 0.67$ \\
Writing & $2.84 \pm 0.92$ & $3.53 \pm 0.66$ \\
\hline
\end{tabular}

Table 4 Health before and after yoga intervention

\begin{tabular}{lll}
\hline Health & PRE & POST \\
\hline Eyesight & $3.02 \pm 0.91$ & $3.62 \pm 0.62$ \\
Sports & $2.89 \pm 0.94$ & $3.57 \pm 0.63$ \\
Sickness & $2.95 \pm 0.89$ & $3.61 \pm 0.62$ \\
Health & $3.00 \pm 0.88$ & $3.64 \pm 0.59$ \\
\hline
\end{tabular}

\section{Improvements in individual domains in overall sample:}

There was a significant (all p's $<0.001$ ) suggesting improvement in all domains in the total sample of 7601 students. Those who fared poor, below average and average in pre assessment showed improvement at post assessment with many of them faring average and good on these domains. Learning (Oral and written expression, mathematical ability) behaviour, cognitive functions (attention, memory, concentration, IQ) improved significantly indicating overall personality development in children.

Table 5 Cognitive abilities following yoga intervention

\begin{tabular}{lll}
\hline Cognitive abilities & Pre & Post \\
\hline Intellect & $2.82 \pm 0.84$ & $3.49 \pm 0.65$ \\
Memory & $2.74 \pm 0.87$ & $3.45 \pm 0.66$ \\
Concentration & $2.75 \pm 0.9 \mathrm{I}$ & $3.50 \pm 0.66$ \\
Intelligence & $2.85 \pm 0.9 \mathrm{I}$ & $3.52 \pm 0.65$ \\
learning & $2.85 \pm 0.89$ & $3.48 \pm 0.67$ \\
Reasoning & $2.75 \pm 0.9 \mathrm{I}$ & $3.44 \pm 0.69$ \\
Interaction & $2.75 \pm 0.92$ & $3.42 \pm 0.7 \mathrm{I}$ \\
Direct speech & $1.98 \pm 0.7 \mathrm{I}$ & $2.52 \pm 0.6 \mathrm{I}$ \\
Attention & $2.06 \pm 0.70$ & $2.60 \pm 0.57$ \\
\hline
\end{tabular}


Table 6 Negative emotions before and after yoga intervention

\begin{tabular}{lll}
\hline Negative emotions & PRE & POST \\
\hline Unhappy & $.91 \pm 0.76$ & $.66 \pm 0.84^{* * *}$ \\
Fear & $.91 \pm 0.76$ & $.48 \pm 0.64 * * *$ \\
Stubborn & $.8 I \pm 0.75$ & $.4 I \pm 0.63^{* * *}$ \\
Reserved & $.90 \pm 0.72$ & $.47 \pm 0.64^{* * *}$ \\
Impulsive & $.88 \pm 0.74$ & $.46 \pm 0.63^{* * *}$ \\
Loneliness & $.77 \pm 0.74$ & $.39 \pm 0.60^{* * *}$ \\
Laziness & $.80 \pm 0.75$ & $.4 I \pm 0.63^{* * *}$ \\
\hline
\end{tabular}

Table 8 Effect sizes following yoga intervention

\begin{tabular}{|c|c|c|c|c|c|c|c|}
\hline \multicolumn{2}{|c|}{ Learning and health } & \multicolumn{2}{|l|}{ Cognition } & \multicolumn{2}{|l|}{$\begin{array}{l}\text { Positive emotions and } \\
\text { behaviours }\end{array}$} & $\begin{array}{l}\text { Negative emotions } \\
\text { and behaviors }\end{array}$ & \multirow{2}{*}{ Effect size } \\
\hline Post-pre & Effect size & Post-pre & Effect size & Post-pre & Effect size & Post-pre & \\
\hline Oral change & $\mathrm{I} .48$ & Intellect change & 0.65 & Discipline change & 0.65 & Unhappy change & -0.21 \\
\hline Listening change & 0.99 & Memory change & 0.73 & Accommodating change & 0.66 & Fear change & -0.47 \\
\hline Reading change & 1.09 & Concentration change & 0.74 & Respect change & 0.60 & Stubborn change & -0.43 \\
\hline Writing change & 1.12 & Intelligence change & 0.65 & Organization capacity change & 0.66 & Reserved change & -0.48 \\
\hline Eyesight change & 1.12 & Learning change & 0.61 & Social change & 0.62 & Impulsive change & -0.46 \\
\hline Sports change & 1.02 & Reasoning change & 0.65 & Obedience change & 0.59 & Loneliness change & -0.43 \\
\hline Digestion change & 1.12 & Interaction change & 0.64 & Self-confidence change & 0.64 & Laziness change & -0.43 \\
\hline Sickness change & 1.10 & Direct speech change & 0.64 & & & & \\
\hline Health change & 1.12 & Attention change & 0.63 & & & & \\
\hline
\end{tabular}

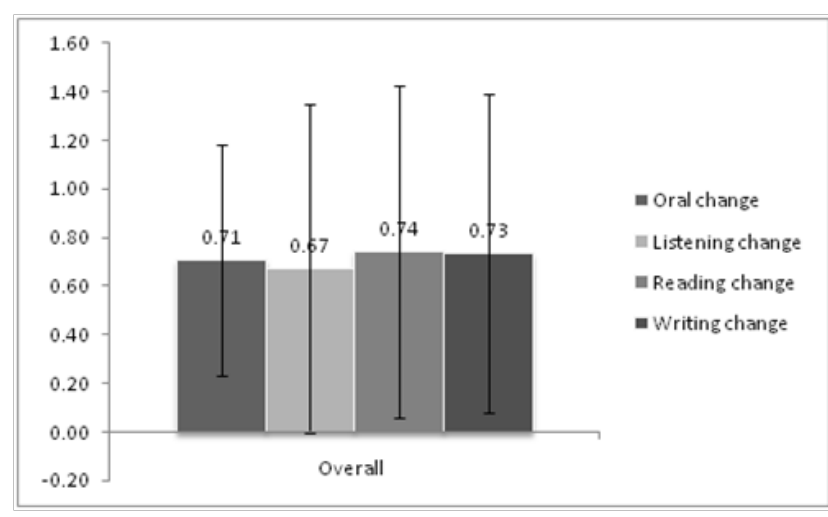

Figure I Change in learning ability following yoga intervention (Learning Change).

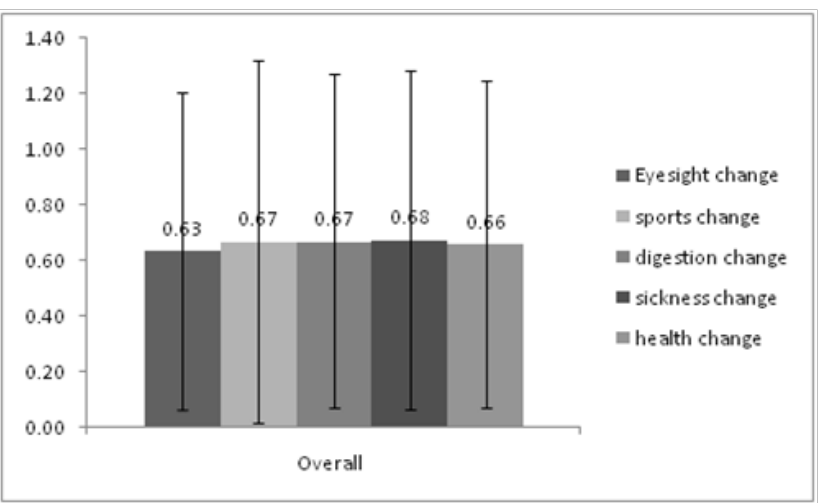

Figure 2 Health change following yoga intervention (Health Change).

\section{Discussion}

The results of our study suggest an improvement in learning and health, significant reduction in negative health behaviours,
Table 7 Positive emotions before and after yoga intervention

\begin{tabular}{lll}
\hline Positive emotions & PRE & POST \\
\hline Discipline & $2.93 \pm 0.92$ & $3.58 \pm 0.62$ \\
Accommodating & $2.10 \pm 0.69$ & $2.63 \pm 0.54$ \\
Respect & $2.16 \pm 0.69$ & $2.64 \pm 0.54$ \\
Organization capacity & $2.01 \pm 0.68$ & $2.55 \pm 0.58$ \\
Social & $2.12 \pm 0.68$ & $2.63 \pm 0.55$ \\
Obedience & $2.14 \pm 0.69$ & $2.62 \pm 0.55$ \\
\hline
\end{tabular}

improvement in cognition and positive emotions. The effect sizes for improvement were largest for learning and health and moderate for cognition, positive and negative emotions and behaviour. Though the high effect sizes could be due to absence of a control group, they nevertheless show benefit finding on the above measures.

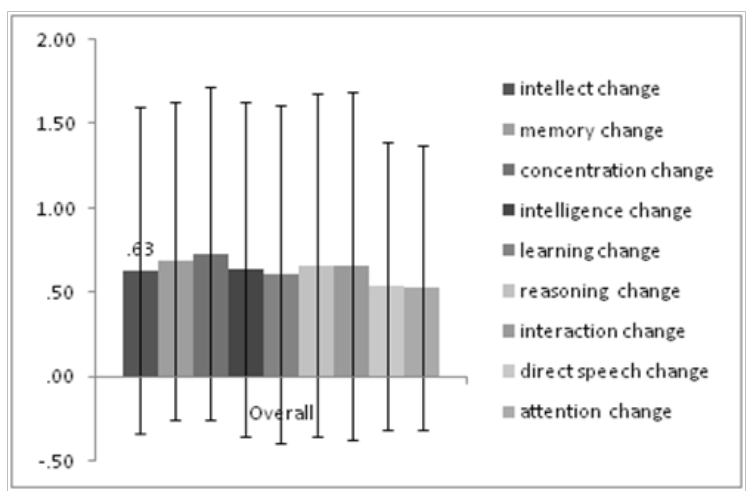

Figure 3 Cognition Change following yoga intervention.

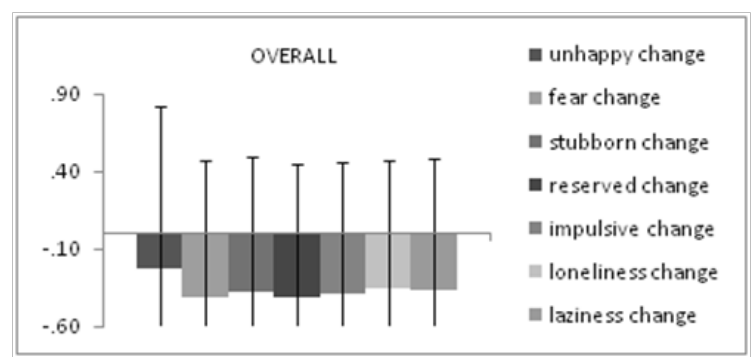

Figure 4 Negative Emotions Change following yoga intervention.

The intervention was carried out in early teen population where in behavioural changes are profound due to influence of sex hormones in this growth period. Surveys have shown prevalence of psychosocial problems in this age group to be around $10-40 \% \cdot{ }^{30-32}$ This is an age wherein teens experience externalizing behavioural problems such as 
confusion, personality conflicts, educational difficulties, substance abuse, hyperactivity, or internalizing emotional upheavals such as anxiety or depression..$^{32-34}$ This coupled with transition stress of moving from primary school to high school can add to the prevailing psychosocial disturbance. $^{32}$

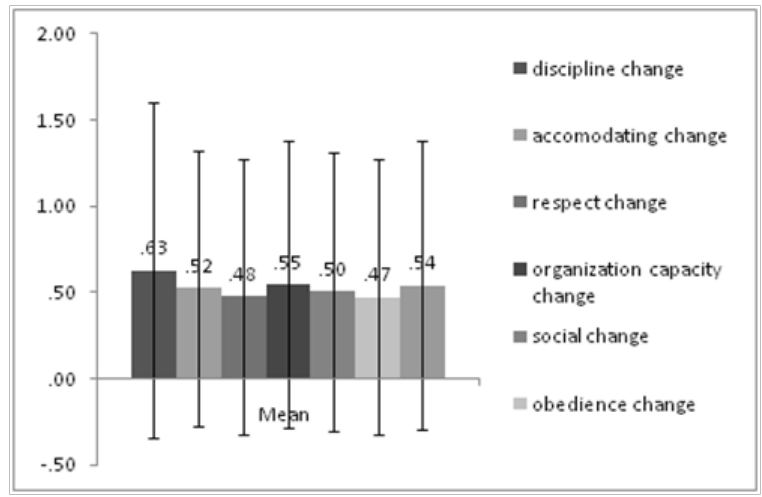

Figure 5 Positive Emotions Change following yoga intervention.

Our results are similar to earlier observations that have shown yoga to help improve learning, self-esteem, reduce anxiety, depression, aggression, impulsiveness, shyness and other negative emotions seen in teenagers..$^{35,29}$ These observations are similar to those gained by using physical education (exercise) and activity that have shown improvements in self-esteem, performance and learning on these measures. ${ }^{36}$

Yoga is training in internal awareness and relaxation and teens can appreciate their endurance with postures, flexibility, and strength and internalize their self-progress over time in a non-competitive environment. ${ }^{37}$ This aspect of yoga could help facilitate adherence to being physically active and adhere to a planned physical regimen. Salutatory effects of exercise could have helped reduce aggressiveness, reduce emotional upheavals, laziness, and improve mood and wellbeing. ${ }^{38}$ This could have brought about a decrease in stress, improved memory, attention span, and learning. ${ }^{39}$

One of the major limitations in our study was the results may be prone for bias as this was a state sponsored program and improvements could have been shown by the teacher as benefits of this program. However we had a part of scoring done by class teacher who was not the trained yoga instructor and part of the study about health and behaviour was also scored by the parents to obfuscate this problem. Secondly, having a comparator arm could have delineated the effects of yoga clearly from physical exercise. Third, the questionnaire was more or less subjective and objective valuation of benefit could not be ascertained. Fourth, having participated in a group yoga program could have facilitated group bonding and support that could have contributed to increased wellbeing. However, despite these limitations the geographical extent and diversity and size of study of population add significant credibility and power to this observational study. Further randomized control trials with exercise as a control intervention are needed to validate these findings in a controlled sample population.

\section{Conclusion}

The results offer support for beneficial effects of yoga intervention in improving learning, cognitive abilities, health and behaviour in high school children. The results also suggest that imparting yoga in school is a feasible option and can be integrated with the routine physical education. Further randomized controlled trials are needed to validate this intervention.

\section{Acknowledgments}

None.

\section{Conflicts of interest}

Author declares there are no conflicts of interest.

\section{Funding}

None.

\section{References}

1. Karande S, Kulkarni M. Poor school performance. Indian J Pediatr. 2005;72(11):961-967.

2. Compas BE, Connor-Smith JK, Saltzman H, et al. Coping with stress during childhood and adolescence: problems, progress, and potential in theory and research. Psychol Bull. 2001;127(1):87-127.

3. Pratinidhi AK, Kurulkar PV, Garad SG, et al. Epidemiological aspects of school dropouts in children between 7-15 years in rural Maharashtra. Indian J Pediatr. 1992;59(4):423-427.

4. Jayachandran, Usha. How High Are Dropout Rates in India? Economic and political weekly. 2007;42(11):982.

5. Farzana A. The impact of school meals on school participation: evidence from rural India. Journal of Development Studies. 2011;47(11):16361656.

6. Strauss CC, Lahey BB, Jacobsen RH. The relationship of three measures of childhood depression to academic underachievement. J Appl Dev Psychol. 1982;3(4):375-380.

7. Rapport MD, Denney CB, Chung KM. Internalizing behavior problems and scholastic achievement in children: Cognitive and behavioral pathways as mediators of outcome. J Clin Child Psychol. 2001;30(4):536-551.

8. Lefkowitz MM, Tesiny EP. Depression in children: prevalence and correlates. J Consult Clin Psychol. 1985;53(5):647-656.

9. McClure E, Rogeness GA, Thompson NM. Characteristics of adolescent girls with depressive symptoms in a so-called normal sample. $J$ Affect Disord. 1997; 42(2-3):187-197.

10. Hodges K, Plow J. Intellectual ability and achievement in psychiatrically hospitalized children with conduct, anxiety, and affective disorders. $J$ Consult Clin Psychol. 1990;58(5):589-595.

11. Vincenzi H. Depression and reading ability in sixth-grade children. $J$ Sch Psychol. 1987;25(2):155-160.

12. Wilkinson PO, Goodyer IM. Attention difficulties and mood-related ruminative response style in adolescents with unipolar depression. $J$ Child Psychol Psychiatry. 2006;47(12):1284-1291.

13. Muris P, van der Pennen E, Sigmond R, et al. Symptoms of anxiety, depression, and aggression in non-clinical children: Relationships with self-report and performance-based measures of attention and effortful control. Child Psychiatry Hum Dev. 2008;39(4):455-467.

14. Livingston RS, Stark KD, Haak RA. Neuropsychological profiles of children with depressive and anxiety disorders. Child Neuropsychol. 1996;2(1):48-62.

15. Cole DA, Martin JM, Powers B, et al. Modeling causal relations between academic and social competence and depression: A multitraitmultimethod longitudinal study of children. J Abnorm Psychol. 1996;105(2):258-270.

16. BERD (Benesse Educational Research and Development Center). 4th survey of attitudes toward study and actual learning in elementary and junior high school students. Spear LP: The adolescent brain and age-related behavioral manifestations. Neurosci Biobehav Rev. 2000;24:417-63. 
17. Centers for Disease Control and Prevention Physical activity levels among children aged 9-13. Morbidity Weekly Report. 2002;52(SS33):785-788

18. Coopersmith, S. The antecedents of self-esteem. Freeman \& Company San Francisco, USA. 1967.

19. Horn TS, Claytor R P. Developmental aspects of exercise psychology. Exercise psychology: The influence of physical exercise on psychological processes. John Wiley \& Sons, New York, USA. 1993.

20. Greenberg D, Oglesby C .Mental health dimensions. Presidents Council on Physical Fitness and Sports Report (Section IV). 1996.

21. Ross A, Thomas S. The health benefits of yoga and exercise: a review of comparison studies. J Altern Complement Med. 2010;(1):3-12.

22. Telles S, Nagarathna R, Nagendra HR. Breathing through a particular nostril can alter metabolism and autonomic activities. Indian J Physiol Pharmacol. 1994;38(2):133-137.

23. Marshall RS, Basilakos A, Williams T, et al. Exploring the benefits of unilateral nostril breathing practice post-stroke: attention, language, spatial abilities, depression, and anxiety. J Altern Complement Med. 2014;20(3):185-194.

24. Karthik PS, Chandrasekhar M, Ambareesha K, et al. Effect of pranayama and suryanamaskar on pulmonary functions in medical students. $J$ Clin Diagn Res. 2014;(12):BC04-BC06.

25. Cowen VS. Functional fitness improvements after a worksite-based yoga initiative. J Bodyw Mov Ther. 2010;14(1):50-54.

26. Krishna BH, Pal P, GK P, et al. Effect of yoga therapy on heart rate, blood pressure and cardiac autonomic function in heart failure. $J$ Clin Diagn Res. 2014;8(1):14-16.

27. D'souza C, Avadhany ST. Effects of yoga training and detraining on physical performance measures in prepubertal children--a randomized trial. Indian J Physiol Pharmacol. 2014;58(1):61-68.

28. Naveen KV, Nagarathna R, Nagendra HR, et al. Yoga breathing through a particular nostril increases spatial memory scores without lateralized effects. Psychol Rep. 1997;81(2):555-561
29. Manjunath NK, Telles S. Spatial and verbal memory test scores following yoga and fine arts camps for school children. Indian J Physiol Pharmacol. 2004;48(3):353-356.

30. Bridges KA, Melody SM. Yoga, physical education, and self-esteem: off the court and onto the mat for mental health. Californian Journal of Health Promotion. 2007;5(2):13-17.

31. Gupta I, Verma M, Singh T, Gupta V. Prevalence of behavioral problems in school going children. Indian J Pediatr. 2001;68(4):323-326.

32. Jellinek MS, Murphy JM, Robinson J, et al. Pediatric symptom checklist: Screening school-age children for psychosocial dysfunction. J Pediatr. 1988;112(2):201-209.

33. Sood N, Misra G. Home environment and problem behaviour in children. J Personality Clin Studies. 1995;11:23-32.

34. Anita, Gaur DR, Vohra AK, Subash S, et al. Prevalence of Psychiatric morbidity among 6 to $14 y \mathrm{rs}$ old children. Indian J Commun Med. $2003 ; 28: 133-137$

35. Gupta SC, Dabral SB, Nandan D, et al. Psychosocial behavioral problems in urban primary school children. Indian J Commun Health. 1997;9:18-21

36. Noggle JJ, Steiner NJ, Minami T, et al. Benefits of yoga for psychosocial well-being in a US high school curriculum: a preliminary randomized controlled trial. J Dev Behav Pediatr 2012;33(3):193-201.

37. Moore JB, Mitchell NG, Bibeau WS, et al. Effects of a 12-week resistance exercise program on physical self-perceptions in college students. Res $O$ Exerc Sport. 2011;82(2):291-301.

38. White LS. Reducing stress in school-age girls through mindful yoga. $J$ Pediatr Health Care. 2012;26(1):45-56.

39. Khalsa SB, Hickey-Schultz L, Cohen D, et al. Evaluation of the mental health benefits of yoga in a secondary school: a preliminary randomized controlled trial. The journal of behavioral health services \& research. 2012;39(1):80-90. 